ORIGINAL ARTICLE

\title{
Presenting features of inflammatory bowel disease in Great Britain and Ireland
}

\author{
A Sawczenko, B K Sandhu
}

Arch Dis Child 2003;88:995-1000

See end of article for authors' affiliations

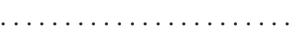

Correspondence to: Professor B K Sandhu, Department of Gastroenterology, Bristol Children's Hospital, Upper Maudlin Street, Bristol BS2 8BJ, UK;

bhupinder.sandhu@

ubht.swest.nhs.uk

Accepted 7 January 2003
Background: Reports from individual referral centres suggest that a significant proportion of children with inflammatory bowel disease (IBD) present after prolonged delays and with impaired growth.

Aims: To prospectively document the presenting features, delay in presentation, disease localisation, and growth in newly diagnosed cases of IBD.

Methods: For 13 months, between June 1998 and June 1999, 3247 paediatricians, adult gastroenterologists, and surgeons across the UK and Ireland were prospectively surveyed each month and asked to report every newly diagnosed case of childhood IBD.

Results: A total of 739 new IBD cases aged less than 16 years were identified. Only one quarter of Crohn's disease (CD) cases presented with the "classic triad" of diarrhoea, weight loss, and abdominal pain; nearly half did not report diarrhoea. The median delay from onset of symptoms to diagnosis was 5 months (mean 11 months), with one fifth having symptoms of more than one year. Delays were most common in $C D$ and in younger children. Short stature was noted only in those with $C D$ and not with ulcerative colitis. One fifth of $C D$ cases had disease activity in the jejunum and this group had significantly reduced stature. lleo-colonic involvement was documented in most CD cases, with only a small minority having isolated ileal or isolated colonic disease. Pan-colitis was reported in most UC cases, with very few having only an isolated proctitis.

Conclusions: Many children are diagnosed after prolonged delays and have growth failure. Improved knowledge of the presenting features of IBD, and earlier investigation of suspected cases, may help reduce the delays noted.
$\mathrm{D}$ espite the apparent increase in incidence of childhood IBD, ${ }^{1}$ many fundamental epidemiological observations remain to be clarified, largely because clinical reports have tended to come from individual referral centres. The literature is unclear, for example, as to whether Crohn's disease, ulcerative colitis, and indeterminate colitis have the same age of onset, or what proportion of children are growth impaired. Several studies ${ }^{2-4}$ have suggested that prolonged diagnostic delays occur in a substantial proportion of IBD cases, but it is not clear whether such delays might be due to the referral process to such centres of excellence.

In recent years, with the widespread adoption of colonoscopy and oesophagogastroduodenoscopy (OGD), and the routine use of histology, the ability to localise disease has improved. Crohn and colleagues initially described "regional ileitis", but with the adoption of more rigorous investigation into routine clinical practice there has been increasing recognition of the widespread extent of Crohn's disease, with microscopic disease being identified throughout the gastrointestinal tract in a substantial proportion of children. ${ }^{5}$ In adult series ulcerative colitis is predominately confined to the rectum or left side of the colon, ${ }^{6}$ but in children there is some evidence that the disease may be more extensive. ${ }^{7}$ The genetic or prognostic implications of precise disease localisation are not as yet known, but they may be important. In adult series macroscopic disease localisation remains stable over time, ${ }^{8}$ and phenotype-genotype associations have recently been described. ${ }^{9}$

In order to provide an evidence base for understanding the epidemiology of childhood IBD, a prospective survey was undertaken through out Great Britain and Ireland. ${ }^{10} \mathrm{~A}$ total of 739 children aged less than 16 were identified, equating to an annual incidence of 5.2 (95\% CI 4.8 to 5.6) per 100000 per year. This is the largest population based series yet reported.
In this paper details of their presenting symptoms, delay in presentation, growth, and extent of disease are reported. Examination of this large series has helped clarify features of rarer subgroups, such as the under $5 \mathrm{~s}$ and those with orofacial granulomatosis.

\section{METHODS}

For 13 months between 1 June 1998 and 30 June 1999, newly diagnosed cases of IBD were prospectively identified in Great Britain and Ireland, by the British Paediatric Surveillance Unit (BPSU), the British Society of Gastroenterology Research Unit (BSGRU), and the Paediatric Register of Inflammatory Bowel Disease (PRIBD). Details about each case were obtained from postal questionnaires, as has been previously described. ${ }^{10}{ }^{11}$

As part of the BPSU survey respondents were asked to report common symptoms by identifying them from a list of six, and to also add other symptoms using free text. Reporters were asked "when was the diagnosis made" and "when were symptoms of IBD first noticed by child or parent"; the interval between these time points being termed the "delay" in presentation. BPSU reporters were also asked to indicate from a list of 10 sites where "disease activity" was observed, as determined from "clinical, radiological, or histological examinations". No other guidance was given in the questionnaire as to what the reporters should define as

Abbreviations: BPSU, British Paediatric Surveillance Unit; BSGRU, British Society of Gastroenterology Research Unit; CD, Crohn's disease; $\mathrm{Cl}$, confidence interval; $\mathrm{GP}$, general practitioner; IBD, inflammatory bowel disease; IC, indeterminate colitis; OGD,

oesophagoduodenoscopy; PRIBD, Paediatric Register of Inflammatory Bowel Disease; RR, relative risk; UC, ulcerative colitis 
"disease activity". As part of the BSGRU questionnaire, adult gastroenterologists and surgeons were asked for the "date of presentation (defined as date of first contact (as outpatient or inpatient) leading to diagnosis)", "date of diagnosis", and "duration of symptoms before presentation".

In this report, cases of Crohn's disease and orofacial granulomatosis have been included together under the term "Crohn's disease" in the text and figures unless otherwise stated. Height and weight results were converted into standard deviation $\mathrm{Z}$ scores using the nomogram of the Child Growth Foundation, London. ${ }^{12}$ Ethnicity was defined using the criteria of the Office of National Statistics, London, and the term "Asian" refers to those reported to be of Indian, Pakistani, or Bangladeshi origin.

\section{RESULTS}

There were 739 incident IBD cases aged less than 16 years diagnosed between 1 June 1998 and 30 June 1999 in Great Britain and Ireland: 431 Crohn's disease, 11 orofacial granulomatosis, 86 indeterminate colitis, and 211 ulcerative colitis cases. ${ }^{11}$

\section{Presenting symptoms and signs (table 1)}

Details of presenting symptoms and signs were available for $84 \%(623 / 739)$ of cases.

The most common presenting symptoms of Crohn's disease were abdominal pain, weight loss, and diarrhoea; and for ulcerative and indeterminate colitis diarrhoea, bleeding, and abdominal pain. A substantial minority of Crohn's cases (44\%, 165/379) did not report diarrhoea, and just 25\% presented with the "classic triad" of abdominal pain, diarrhoea, and weight loss. Even if the symptom of pain was not included, less than half $(45 \%, 170 / 379)$ reported the combination of diarrhoea and weight loss. Seven per cent $(25 / 379)$ were reported to have an anal fistula, abscess, or ulcer.

\section{Height and weight at diagnosis (table 2, fig 1)}

Details of height were available for $73 \%$ (539/739) and of weight for $82 \%(605 / 739)$ of cases.

For children with Crohn's disease both mean height and weight Z scores were significantly reduced. Females were significantly lighter than males (mean Z score of -1.30 (95\% CI -1.07 to -1.53 ) versus mean $Z$ score of -0.94 (95\% CI -0.76 to -1.12$), p=0.027, t$ test). For Crohn's cases there was a negative correlation between length of the delay and height $\mathrm{Z}$ score $(r=-0.22, \mathrm{p}<0.001)$. There were no significant correlations between the length of delay and weight Z score, or between age at diagnosis and height or weight $\mathrm{Z}$ scores.

The mean height $\mathrm{Z}$ scores of children with ulcerative and indeterminate colitis were not significantly reduced. Ulcerative colitis cases were significantly underweight, though less so than Crohn's cases. There were no sex differences.

Cases of Asian origin were not significantly shorter or lighter than other ethnic groups.

\section{Age of onset of symptoms and at diagnosis (table 3, fig 2)}

Details were available for $78 \%$ (579/739) of cases. The median age of the recalled onset of symptoms was not significantly different between cases of Crohn's disease, indeterminate colitis, and ulcerative colitis. The recalled age of onset of symptoms for cases of Crohn's disease with ileal activity appeared to be younger than for cases without ileal involvement (median 11.5 versus 12.0 years, $p=0.08$, Mann-Whitney).

Crohn's cases were older at diagnosis than indeterminate colitis cases but were not older than ulcerative colitis cases ( $p=0.021$ and $p=0.059$, Mann-Whitney, respectively).

The median age at diagnosis for all the 739 cases was 12.6 years (range $0.35-16) ; 4 \%(29 / 739)$ were aged less than 5 years and $17 \%(125 / 739)$ were between 5 and 10 years.

\section{Delay in diagnosis (table 3, fig 3)}

Details were available for $78 \%$ (579/739) of cases. The median delay for all cases of IBD was 5 months, ranging from $<1$ month to 9 years (mean 11 months). Sixty per cent of IBD cases were reported to have had a delay of less than 6 months, $19 \%$ a delay of $6-12$ months, $14 \%$ a delay of $1-3$ years, and $7 \%$ a delay of more than 3 years (345/579, 109/579, $83 / 579$, and $42 / 579$ respectively). There were no associations between length of delay, sex, and family history of IBD.

\begin{tabular}{|c|c|c|c|}
\hline & $\begin{array}{l}C D \\
(n=379)\end{array}$ & $\begin{array}{l}\text { IC } \\
(n=72)\end{array}$ & $\begin{array}{l}\text { UC } \\
(n=172)\end{array}$ \\
\hline \multicolumn{4}{|l|}{ Common symptoms } \\
\hline Abdominal pain & $274(72 \%)$ & $54(75 \%)$ & $106(62 \%)$ \\
\hline Diarrhoea & $214(56 \%)$ & $56(78 \%)$ & $127(74 \%)$ \\
\hline Bleeding & $84(22 \%)$ & $49(68 \%)$ & $145(84 \%)$ \\
\hline Weight loss & $220(58 \%)$ & $25(35 \%)$ & $53(31 \%)$ \\
\hline Lethargy & $103(27 \%)$ & $10(14 \%)$ & $20(12 \%)$ \\
\hline Anorexia & $94(25 \%)$ & $9(13 \%)$ & $11(6 \%)$ \\
\hline \multicolumn{4}{|l|}{ Other symptoms } \\
\hline Arthropathy & 28 & 3 & 11 \\
\hline Nausea/vomiting & 22 & 1 & 1 \\
\hline Constipation/soiling & 4 & & \\
\hline Psychiatric symptoms & 3 & & \\
\hline Secondary amenorrhoea & 1 & & 1 \\
\hline \multicolumn{4}{|l|}{ Signs } \\
\hline Anal fistula & 17 & & \\
\hline Growth failure/delayed puberty & 14 & 1 & \\
\hline Anal abscess, ulcer & 8 & & \\
\hline Erythema nodosum/rash & 6 & & 1 \\
\hline Liver disease & 3 & 2 & 5 \\
\hline Appendicectomy & 2 & & \\
\hline Toxic megacolon & & & 1 \\
\hline
\end{tabular}




\begin{tabular}{|c|c|c|c|c|c|}
\hline & Mean $\mathrm{Z}$ score $(95 \% \mathrm{Cl})$ & $\begin{array}{l}<10 \text { th centile } \\
(<-1.64 \text { SDS })\end{array}$ & $\begin{array}{l}<3 \text { rd centile } \\
(<-1.96 \text { SDS })\end{array}$ & $\begin{array}{l}<0.04 \text { th centile } \\
(<-2.88 \text { SDS })\end{array}$ & $\mathbf{n}$ \\
\hline \multicolumn{6}{|c|}{ Height } \\
\hline$C D$ & $-0.54(-0.67$ to -0.41$)$ & $17 \%(58)$ & $13 \%(43)$ & $2 \%(8)$ & 338 \\
\hline UC & $-0.12(-0.30$ to 0.05$)$ & $10 \%(14)$ & $3 \%(4)$ & - & 143 \\
\hline IC & $-0.15(-0.44$ to 0.14$)$ & $10 \%(6)$ & $7 \%(4)$ & - & 58 \\
\hline \multicolumn{6}{|c|}{ Weight } \\
\hline$C D$ & $-1.06(-1.21$ to -0.92$)$ & $32 \%(118)$ & $27 \%(95)$ & $7 \%(26)$ & 369 \\
\hline UC & $-0.32(-0.51$ to -0.13$)$ & $15 \%(25)$ & $9 \%(15)$ & $9 \%(15)$ & 165 \\
\hline IC & $-0.17(-0.50$ to 0.17$)$ & $15 \%(11)$ & $11 \%(8)$ & - & 71 \\
\hline
\end{tabular}

Children with Crohn's disease had longer delays than those with ulcerative colitis or indeterminate colitis $(\mathrm{p}<0.01$ and $\mathrm{p}<0.001$, Mann-Whitney, respectively). Children with Crohn's disease were over-represented among those with a delay of more than one year; $18 \%$ had a delay of $1-3$ years, and $9 \%$ a delay of more than 3 years. In comparison, the figures for those with ulcerative colitis were $8 \%$ and $5 \%$ respectively (3/359 and $31 / 359$ versus $12 / 153$ and $7 / 153$ respectively). There was no difference in the length of delay between those with indeterminate or ulcerative colitis.

Presence or absence of specific symptoms (diarrhoea, bleeding, weight loss, lethargy, or anorexia) were not associated with the length of delay for Crohn's disease, or indeterminate or ulcerative colitis; although for all IBD cases the presence of rectal bleeding was associated with a shorter delay (median 5 versus 6 months, $p=0.005$, MannWhitney). For cases of Crohn's disease, oral and perianal
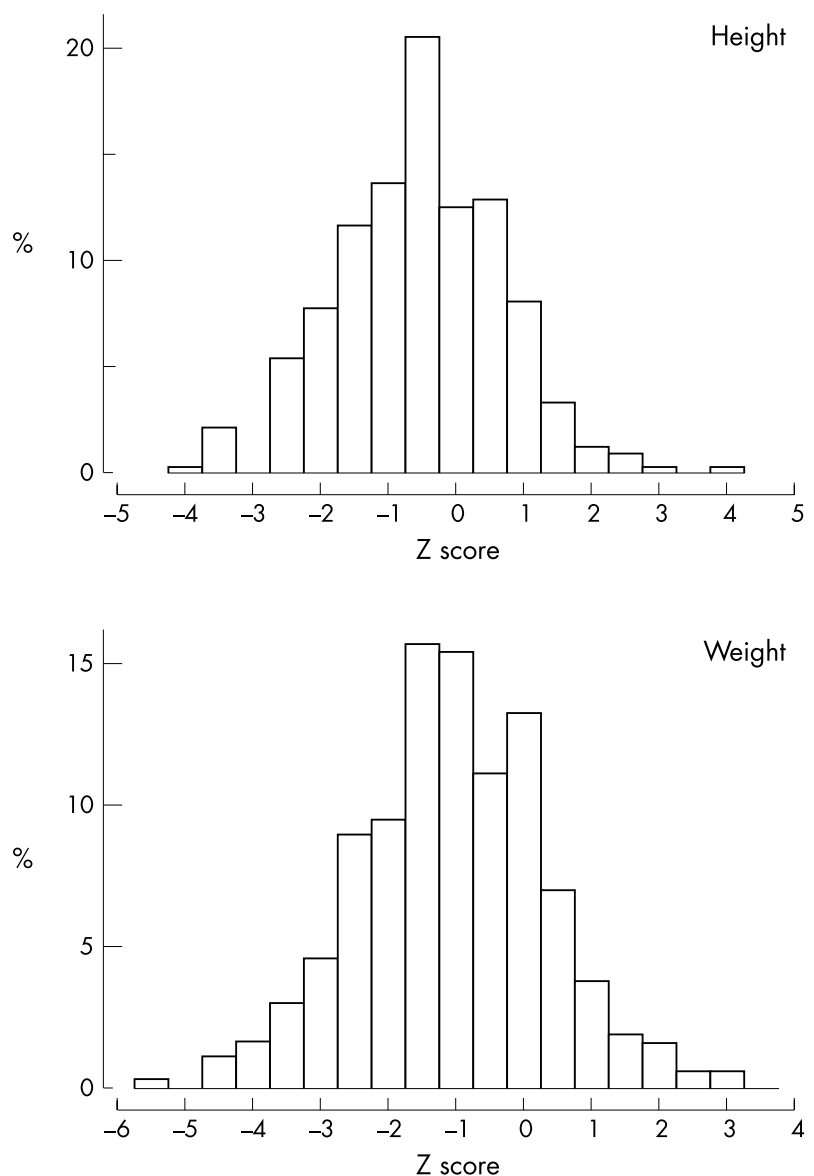

Figure 1 Height and weight $Z$ score of Crohn's cases at diagnosis. disease activity were associated with longer delays (median 8 versus 6 months, $\mathrm{p}=0.04$, and 8 versus 5 months, $\mathrm{p}=0.02$, respectively, Mann-Whitney). Cases with jejunal activity appeared to have longer delays than those without (median of 8 versus 5 months, $\mathrm{p}=0.055$, Mann-Whitney).

There was a negative correlation between the length of delay and the recalled age of onset of symptoms $(r=-0.31$; $p<0.001$, Spearman) for all cases of IBD, with little difference in the individual coefficients for Crohn's disease, or ulcerative or indeterminate colitis. This suggests that features of IBD were more difficult to recognise in younger children.

In $27 \%$ (196/739) of cases details of the age of presentation to the general practitioner (GP) were available. In this small sample just under half of the total delay occurred as a result of children not presenting to GPs and just over half followed presentation to GPs. (The mean (median) time from onset of symptoms to GP was $0.4(0.2)$ months, and from presentation to GP to hospital based diagnosis was 0.5 (0.2) months.) There were no correlations between the length of these two times for individual patients.

\section{Site of disease activity (fig 4)}

The results from the initial investigations undertaken were provided in $83 \%(611 / 739)$ of cases. Children had a variety of combinations of sigmoidoscopy, colonoscopy, oesophagogastroduodenoscopy (OGD), barium enema, barium follow though, and radiolabelled white cell scans.

Figure 4 shows the results of the disease activity by anatomical site for the 214 children that had the combination of OGD, barium follow through, and colonoscopy. For those with Crohn's disease the most commonly affected sites were the terminal ileum and right colon; half had gastroduodenal activity and one fifth jejunal activity. Only 9\% (15/127) had isolated small bowel disease and 7\% (9/127) isolated colonic disease. The majority thus had both colonic and small bowel disease. For cases of ulcerative colitis only $4 \%(1 / 27)$ had disease activity solely confined to the rectum. Eighty one per cent $(22 / 27)$ had disease extending to the right colon-that is, the majority had a pan-colitis. Rectal sparing was noted in $4 \%$ ( $1 / 27)$. Indeterminate colitis had a disease distribution intermediate between that of Crohn's disease and ulcerative colitis.

Relation between site of disease activity and growth For $84 \%$ (364/431) of Crohn's disease cases details were available to undertake an analysis of the relation between disease activity and growth. The presence of jejunal disease activity was associated with both reduced height and weight (mean $\mathrm{Z}$ score of -0.9 versus $-0.5, \mathrm{p}=0.041$; and mean $\mathrm{Z}$ score of -1.6 versus $-1.1, p=0.017$; both $t$ test). Ileal activity was associated with reduced weight (mean $\mathrm{Z}$ score -1.2 versus $-0.8, p=0.02$, $t$ test) but not with reduced height. 
Table 3 Age of onset of symptoms, delay, and age at diagnosis

\begin{tabular}{|c|c|c|c|c|c|c|}
\hline & $\begin{array}{l}\text { Age of onset of } \\
\text { symptoms }\end{array}$ & $\mathbf{n}$ & $\begin{array}{l}\text { Overall delay (onset } \\
\text { to diagnosis) }\end{array}$ & n & Age at diagnosis & $\mathbf{n}$ \\
\hline$C D$ & $11.8(9.8-13.3)$ & 350 & $0.5(0.3-1.0)$ & 350 & $12.9(10.8-14.3)$ & 431 \\
\hline OFG & $7.6(4.5-9.3)$ & 9 & $1.2(0.7-2.3)$ & 9 & $9.9(5.8-11.6)$ & 11 \\
\hline IC & $11.1(9.5-12.8)$ & 64 & $0.3(0.2-0.7)$ & 64 & $11.6(10.3-13.8)$ & 86 \\
\hline UC & $11.7(9.3-13.7)$ & 155 & $0.4(0.2-0.7)$ & 155 & $12.3(10.1-14.1)$ & 211 \\
\hline $\mathrm{CD}+\mathrm{OFG}$ & $11.7(9.6-13.3)$ & 359 & $0.5(0.3-1.1)$ & 359 & 12.8 (10.7-14.2) & 442 \\
\hline
\end{tabular}

Figures are medians (years) with parentheses indicating interquartile range (Q1 to Q3).

There was also a negative relation between the presence of oesophageal activity and height, mean $\mathrm{Z}$ score of -0.6 versus $-0.4, \mathrm{p}=0.045$ ( $t$ test), but no relation between jejunal activity and oesophageal activity. Because children with jejunal activity appeared to have longer delays, we undertook linear regression modelling with height $\mathrm{Z}$ score as the dependent variable and length of delay and presence or absence of jejunal disease or oesophageal disease as the independent variables; in this model only length of delay remained significant.

\section{Sex}

There was a male preponderance in Crohn's disease (62\%) and an equal sex ratio in ulcerative and indeterminate colitis cases, as previously reported. ${ }^{11}$ The sex ratio of Crohn's cases was further examined by the site of disease activity. For nine of ten anatomical sites there was a male excess (61-68\%) among those with or without disease activity at these sites. Similarly for cases with ileal involvement the male excess was $68 \%$ (157/231). However, for those without ileal involvement the ratio of males fell to $46 \%(45 / 97)$ $\left(\mathrm{p}<0.001, \chi^{2}\right.$ test $)$. Thus Crohn's cases without ileal involvement was the only subgroup not to have a male preponderance.

\section{Under 5s}

Twenty nine cases were aged less than 5 years at diagnosis (the youngest being 4 months): nine Crohn's disease, two orofacial granulomatosis, 11 ulcerative colitis, and seven indeterminate colitis. Thus only a minority of the under $5 \mathrm{~s}$ had Crohn's disease compared to the majority of children

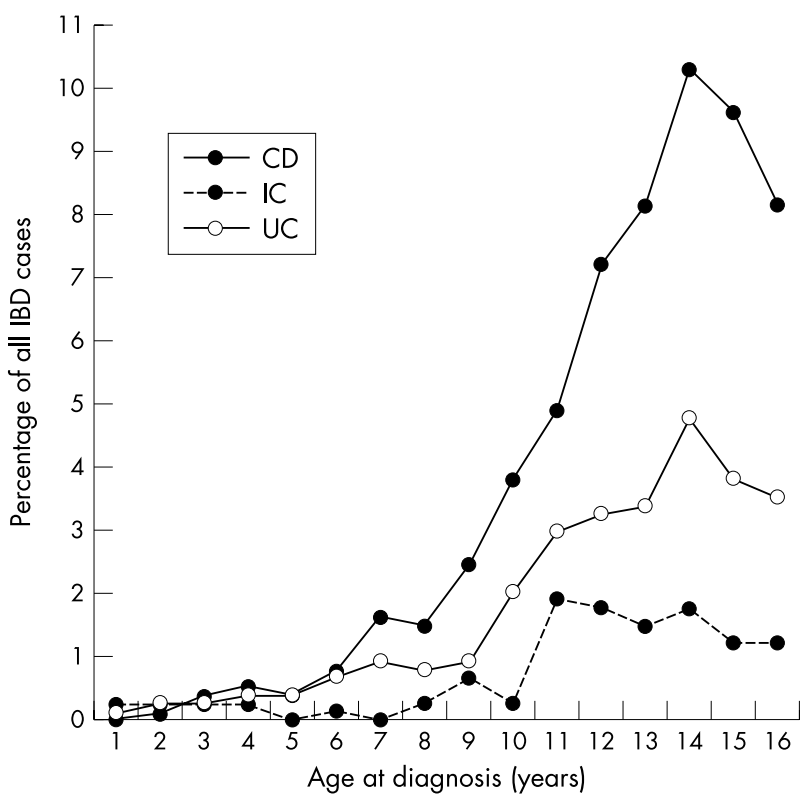

Figure 2 Age at diagnosis. aged $5-16$ years $\left(38 \%(11 / 29)\right.$ versus $61 \%(422), p=0.03, \chi^{2}$ test). There was a significantly greater proportion of children of Asian origin among the under 5s (25\% (5/20) versus 6\% (39/606), relative risk 3.9 (95\% CI 1.7 to 8.8$), p=0.0013)$. The sex ratio, and proportion with a positive family history of IBD, were the same as for older children $(9 \%(2 / 23)$ versus $15 \%(89 / 606)$ respectively, $p=0.42, \chi^{2}$ test $)$.

Abdominal pain was reported less often in younger children. No child under 5 with Crohn's disease presented with the "classic triad" of symptoms, although two with ulcerative colitis did.

\section{Orofacial granulomatosis (table 3)}

Although the numbers are small, cases of orofacial granulomatosis were reported to be significantly younger at the onset of their symptoms, to have the longest delays, and yet to be younger at diagnosis than children with Crohn's disease, or indeterminate or ulcerative colitis. A disproportionate number (3/11) came from Scotland compared to the rest of the British Isles (RR 4.03 (95\% CI 1.07 to 15.25) p $=0.028$ ) and a further three cases came from the northern region of England.

\section{DISCUSSION}

This cohort of 739 children is the largest group of IBD cases yet reported..$^{10}$ For the first time the presenting features, delay to diagnosis, growth, disease extent, sex, and ethnicity have been documented in a single population based group. The only other population based study which documented clinical characteristics in a UK population was a retrospectively collected cohort of 112 Scottish children gathered between 1968 and $1983 .^{3}$

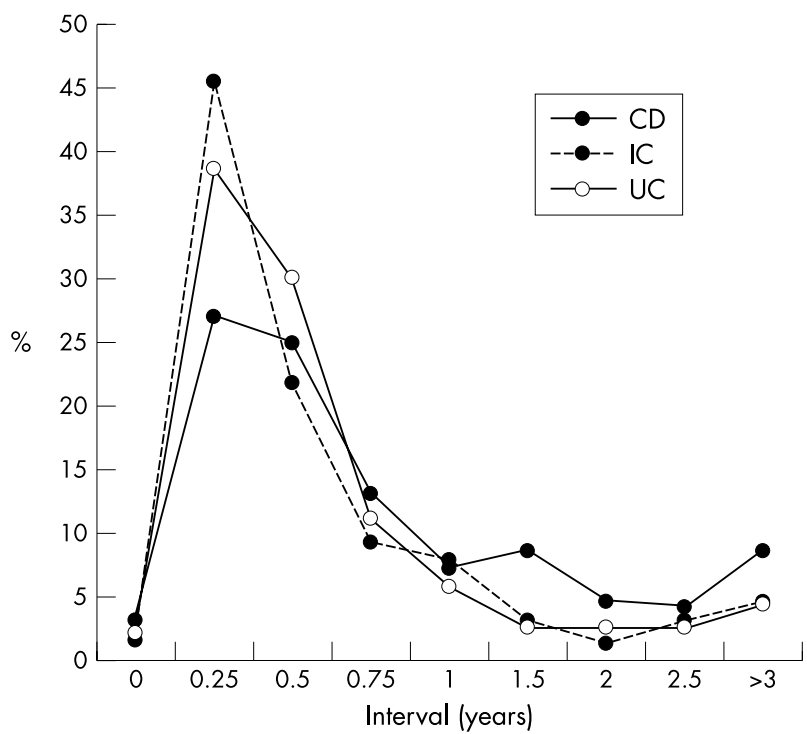

Figure 3 Delay. 


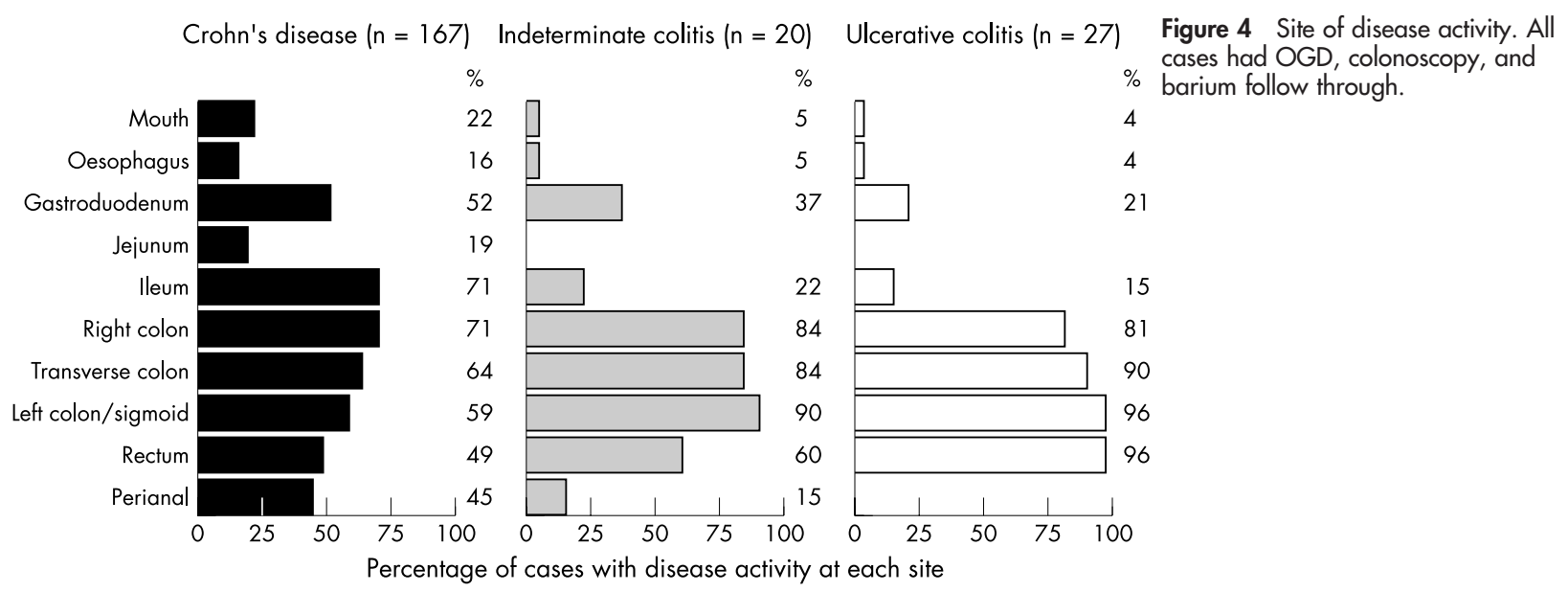

In the current study data were available for $73-100 \%$ of cases. Because of the study's scale, it was not possible to verify details from individual reports, such as the accuracy of height or weight measurements. However, given the large sample size and number of reporting centres it is probable that there was little systematic bias. Although the return of detailed questionnaires was lower in the "adult" BSGRU survey (which was biased towards slightly older children), there was no evidence for example of an age effect on height or weight $\mathrm{Z}$ scores (data not shown).

In this large population based cohort the recalled age of onset of symptoms did not vary by disease type, and were the same for Crohn's disease, ulcerative colitis, and indeterminate colitis. The median delay between onset of symptoms and diagnosis was 5 months (mean 11 months); a fifth of cases reported symptoms of more than one year's durationrising to more than a quarter of Crohn's cases. These delays are shorter than retrospectively reported from a tertiary referral centre, ${ }^{4}$ but longer than those reported in the Scottish population based survey. ${ }^{3}$ As this is the first study to collect such data prospectively, comparisons with previous studies are difficult. It is clear, however, that delay remains inappropriately long for many children, and not only for those with predominately small bowel Crohn's disease. In the UK and Ireland, children generally receive their primary care from community based general practitioners (GPs) that refer to hospital based clinicians for diagnosis and management. Delay could therefore occur at a number of points. In the small proportion of cases where details were available, delay was roughly evenly divided between the time that patients took to present to GPs and the time to hospital based diagnosis.

Given that this study also found a negative relation between age and length of delay, it would appear that both public and professionals need to be aware that IBD occurs in children of all ages and that "classic" colitic symptoms, such as diarrhoea and bleeding, should be promptly investigated. However, many children, especially those with Crohn's disease, present in a "non-classical" manner with nonspecific symptoms such as lethargy and mild abdominal discomfort. One notable finding of this survey was that $44 \%$ of Crohn's cases did not report diarrhoea, and only $25 \%$ presented with the "classic triad" of diarrhoea, pain, and weight loss. Wider use of screening blood tests to look for raised erythrocyte sedimentation rate, $\mathrm{C}$ reactive protein, or platelets, and reduced serum albumin may help in earlier identification of such cases. ${ }^{15}$

Several series have reported that growth impairment is present at diagnosis in both Crohn's and ulcerative colitis cases. In this population based study growth impairment was only found in Crohn's disease. There was a significant negative correlation between length of delay and height in Crohn's disease, suggesting that earlier diagnosis might contribute to lessening these findings by rectifying the growth inhibiting effects of malnutrition and of inflammatory cytokines. ${ }^{16}$ The overall degree of growth impairment for Crohn's cases (a mean of -0.5 SDS) was the same as that reported in a Swedish population based survey. ${ }^{17}$ One important observation in the current study was the association of jejunal disease with a considerably reduced mean SDS score of -0.9 . The literature has previously not emphasised this subgroup with "extensive small bowel" disease. ${ }^{3}{ }^{18}$ It may be that in order to facilitate growth, more aggressive therapy is warranted in this subgroup of patients.

A paediatric or adult gastroenterologist was involved in $96 \%$ of cases in this study. ${ }^{11}$ Reporters were asked to describe the site of "disease activity" as determined from clinical, radiological, or histological examinations. Figure 4 shows the patterns of disease activity obtained from the sample of 214 children who had OGD, barium follow through, and colonoscopy. Crohn's disease was historically described as affecting primarily the terminal ileum. However, we observed that with modern investigative protocols the majority of Crohn's cases had both ileal and right sided colonic disease activity, and only a minority had isolated ileal or isolated colonic disease. In addition, isolated proctitis was uncommon in ulcerative colitis and the majority of children had a pan-colitis. (A separate analysis of all 611 cases where results from a variety of combinations of investigations were available, found that the rates only varied slightly, and were lower for gastroduodenal and right sided colonic activity - that is, greater use of OGD and colonoscopy revealed more disease at these sites (data not shown).) The additional observation of sex differences in the rates of ileal involvement ${ }^{13}{ }^{14}$ suggests that the apparent differences in disease localisation between childhood and adult onset IBD could be due to variations in complex extended haplotypes across a number of genetic loci.

This study has documented the wide extent of disease activity at the presentation of both Crohn's disease and ulcerative colitis. Improved recognition of the presenting features of IBD and wider use of screening and investigative tests may help reduce the delays noted. Growth failure remains a significant problem for many children at diagnosis, especially Crohn's cases with jejunal involvement.

\section{ACKNOWLEDGEMENTS}

This work would not have been possible without the support of the members of the Royal College of Paediatrics and Child Health, the members of the British Society of Gastroenterology, and others who 
reported cases. We thank them. It was supported by the British Society of Paediatric Gastroenterology, Hepatology, and Nutrition and we would like to thank the society and its members.

We wish to especially thank Dr Richard Lynn and Dr Angus Nicoll of the British Paediatric Surveillance Unit of the Royal College of Paediatrics and Child Health, Ms Sarah Mian and Professor Richard Logan of the British Society of Gastroenterology Research Unit, Dr Tim Card of the Department of Public Health Epidemiology, University of Nottingham, Dr Huw Jenkins and Dr David Casson of the Paediatric Register of Inflammatory Bowel Disease, and Prof. Chris Taylor of the Sheffield Children's Hospital.

The study was funded by donations from the National Association of Crohn's and Colitis, SHS International, and the Bristol Paediatric Gastroenterology Fund.

\section{Authors' affiliations}

A Sawczenko, B K Sandhu, Department of Gastroenterology and Nutrition, Bristol Children's Hospital, Bristol, UK

\section{REFERENCES}

1 Armitage E, Drummond H, Ghosh S, et al. Incidence of juvenile-onset Crohn's disease in Scotland. Lancet 1999;353:1496-7.

2 O'Donoghue DP, Dawson AM. Crohn's disease in childhood. Arch Dis Child 1977;52:627-32.

3 Barton JR, Ferguson A. Clinical features, morbidity and mortality of Scottish children with inflammatory bowel disease. QJM 1990;75 423-39.

4 Spray C, Debelle GD, Murphy MS. Current diagnosis, management and morbidity in paediatric inflammatory bowel disease. Acta Paediatr $2001 ; 90: 400-5$
5 Lenaerts C, Roy CC, Vaillancourt M, et al. High incidence of upper gastrointestinal tract involvement in children with Crohn disease. Pediatrics 1989;83:777-81

6 Rubin GP, Hungin AP, Kelly PJ, et al. Inflammatory bowel disease: epidemiology and management in an English general practice population. Aliment Pharmacol Ther 2000;14:1553-9.

7 Michener WM, Farmer RG, Mortimer EA. Long-term prognosis of ulcerative colitis with onset in childhood or adolescence. J Clin Gastroenterol 1979;1:301-5.

8 Louis E, Collard A, Oger A, et al. Behaviour of Crohn's disease according to the Vienna classification: changing pattern over course of the disease. Gut $2001 ; 49: 772-82$.

9 Ahmad T, Armuzzi A, Bunce M, et al. The molecular classification of the clinical manifestations of Crohn's disease. Gastroenterology 2002; 122:854-66

10 Sawczenko A, Sandhu BK, Logan RFA, et al. Prospective survey of childhood inflammatory bowel disease in the British Isles. Lancet 2001;357:1093-4.

11 Sawczenko A, Lynn R, Sandhu BK. Variations in initial assessment and management of inflammatory bowel disease across Great Britain and Ireland. Arch Dis Child 2003;88:990-4.

12 Freeman JV, Cole TJ, Chinn S, et al. Cross-sectional stature and weight reference curves for the UK. Arch Dis Child 1995;73:17-24.

13 Hugot JP, Chamaillard M, Zouali $\mathrm{H}$, et al. Association of NOD2 leucine-rich repeat variants with susceptibility to Crohn's disease. Nature 2001;411:599-603.

14 Ogura $\mathrm{Y}$, Bonen DK, Inohara N, et al. A frameshift mutation in NOD2 associated with susceptibility to Crohn's disease. Nature 2001;41 1:603-6.

15 Beattie RM, Walker-Smith JA, Murch SM. Indications for investigation of chronic gastrointestinal symptoms. Arch Dis Child 1995;73:345-55.

16 Ballinger AB, Camacho-Hubner C, Croft NM. Growth failure and intestinal inflammation. QJM 2001;94:121-5.

17 Hildebrand H, Karlberg J, Kristiansson B. Longitudinal growth in children and adolescents with inflammatory bowel disease. J Pediatr Gastroenterol Nutr 1994; 18:165-73.

18 Puntis J, McNeish AS, Allan RN. Long term prognosis of Crohn's disease with onset in childhood and adolescence. Gut 1984;25:329-36.

\section{ARCHIVIST}

\section{Pharmacogenomics and drug resistant epilepsy}

t's simple really: you have superfamilies of proteins within which there are families within which there are members, and a member may have several, quite different, names. The transporter protein that concerns us here belongs to the ATP binding cassette superfamily of multidrug transporters; more specifically it is a member of subfamily B, in fact member one. So it is the ATP binding cassette subfamily B member 1 transporter (ABCBI transporter). But you could, if you wanted to, call it MDRl or P-glycoprotein 170. (Let's stick with $\mathrm{ABCB} 1$ for now, shall we?) It is a transmembrane glycoprotein that controls entry of lipophilic molecules (including at least four antiepileptic drugs) into the brain by acting as a drug efflux pump, and it may be part of the blood-brain barrier. Up-regulation of ABCBI is associated with drug resistance in cancer, rheumatoid arthritis, and inflammatory bowel disease. ABCBI concentrations are increased in brain lesions causing epilepsy, and many antiepileptic drugs are lipophilic. Now research on patients in London (Asra Siddiqui and colleagues. New England Journal of Medicine 2003;348:1442-8; see also editorial, ibid: 1480-2) has shown that a particular genotype of an $A B C B 1$ gene polymorphism is found more often in patients with drug resistant than with drug responsive epilepsy.

The ABCB1 C3435T polymorphism was genotyped (CC, CT, or TT) for 200 patients with drug resistant epilepsy, 115 with drug responsive epilepsy, and 200 controls (neurological patients without epilepsy. (The age distribution is not stated but they were presumably mainly, if not all, adults.) The genotype distribution (CC; CT; TT) was $27.5 \% ; 53 \%$; $19.5 \%$ in the patients with drug resistant epilepsy, $15.7 \% ; 54.8 \% ; 29.6 \%$ in the drug sensitive group, and $18.5 \%, 58 \%, 23.5 \%$ in the controls. Patients with drug resistant epilepsy were 2.7 times more likely to have the CC rather than the TT genotype than were patients with drug sensitive epilepsy. The researchers argue that the polymorphism itself, because it is silent (does not alter the amino acid sequence), is unlikely to be the cause of multidrug resistance but is more likely to be associated with another variant which is the cause.

Changes in transporter protein genes may be associated with resistance to antiepileptic drugs. 